DOI: https://doi.org/10.5007/1980-3532.2017n17p15

\title{
Comunismo, o inimigo do Ocidente - Entre o exterminismo e a resistência
}

\author{
Communism, the enemy of the Occident - Between exterminism \\ and resistance
}

\author{
Eliton Felipe de Souza \\ Universidade do Estado de Santa Catarina (UDESC) \\ Doutorando em História \\ elitonfelipe@gmail.com
}

\begin{abstract}
Resumo: este trabalho pretende traçar um panorama sobre a trajetória do Partido Comunista Brasileiro desde a sua origem, entre 1906 e 1922, até o período de redemocratização do país, após a ditadura militar, em 1985, procurando evidenciar o quanto o partido sofreu com a repressão e com as diversas intervenções do Estado, principalmente no contexto de Guerra Fria do Pós-Segunda Guerra Mundial. Para isso, algumas categorias propostas por Thompson foram muito caras a produção deste artigo, como o de Exterminismo, diretamente vinculada a Guerra Fria e, no caso deste trabalho, a eliminação dos comunistas, e o de Alteridade do Outro, que servira de base para a criação do inimigo em comum das ditaduras latino-americanas, novamente, o comunismo.
\end{abstract}

Palavras-chave: Comunismo. Alteridade do outro. Partido Comunista Brasileiro. Repressão. Exterminismo.

Abstract: This paper intends to give an overview of the trajectory of Brazilian Communist Party since its was create, between 1906 and 1922, until the period of re-democratization of the country, after the military dictatorship, in 1985, trying to evidence how much the party suffered with repression and with the many State interventions, especially in the Cold War context after post World War II. For this, some categories proposed by Thompson were very important to the production of this article, like the Exterminism, directly linked to Cold War and, in the case of this paper, the elimination of the communists, and the Otherness, that served as base for the creation of the common enemy of Latin American dictatorship, again, the communism.

Keywords: Communism. Otherness. Brazilian Communist Party. Repression. Exterminism.

Originais recebidos em: 12/09/2017

Aceito para publicação em: 17/04/2018

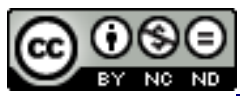

Este trabalho está licenciado sob uma Licença Creative Commons Atribuição-Uso Não-Comercial-Vedada a criação de obras derivadas 3.0 Unported License.

Revista Em Debate (UFSC), Florianópolis, volume 17, p. 15-35, 2017. ISSNe 1980-3532 


\section{Introdução}

Esse artigo propõe um olhar sobre a história da militância comunista brasileira: do congresso de fundação do partido, em março de 1922, até o retorno a legalidade com o fim da Ditadura Militar, em 1985. Neste ínterim, então, pretendendo compreender os motivos que levaram este grupo político a passar a maior parte de sua existência na ilegalidade. Como e por quê o Partido Comunista foi demonizado e tratado como inimigo pelas elites políticas e econômicas brasileiras, assim como por diversos chefes de governo.

Parte da compreensão deste caso se dá por meio das obras do historiador marxista Edward Palmer Thompson, responsável por cunhar a categoria de exterminismo, aplicada aqui a repressão levada a cabo pelo Estado brasileiro contra os militantes comunistas na intenção de eliminar o dissenso e a força política destes. Este trabalho percorre o trabalho de Thompson de modo a compreender as relações políticas e sociais que envolveram os comunistas brasileiros durante o século XX. Abarcando desde o conceito de classe, trabalhado pelo autor, a luta de classes e as questões da dialética, chegando, enfim, às categorias de alteridade do outro e exterminismo.

Conhecer as contribuições de Thompson para a produção historiográfica e sociológica são de suma importância, pois o autor foi capaz de compreender a relevância da realidade histórica como processo e a experiência como relação entre os sujeitos sociais e a consciência social, num constante diálogo entre teoria e ação social. Este artigo, portanto, pretende apresentar um olhar sobre a história da militância do PCB, utilizando para isso categorias thompsianas capazes de lançar luz sobre a trajetória político-social do partido contra a repressão das elites econômicas e do Estado.

\section{"Proletários de todos os países, uni-vos!" - Surge o Partido Comunista Brasileiro}

Impulsionados pela frase final do Manifesto Comunista de Marx e Engels, ao longo dos anos, intelectuais e trabalhadores se articularam em torno de partidos socialistas e do Partido Comunista procurando transformar o modo de produção capitalista: 
as suas perspectivas e propósitos. Declaram abertamente que os seus fins só podem ser alcançados pelo derrube violento de toda a ordem social até aqui. Podem as classes ${ }^{1}$ dominantes tremer ante uma revolução comunista! Nela os proletários nada têm a perder a não ser as suas correntes. Têm um mundo a ganhar (MARX; ENGELS, 2013, p. 64).

Segundo Agosti (2003), o comunismo foi um movimento que interferiu diretamente na vida política e econômica dos países, tanto comunistas quanto capitalistas, entrelaçando tradições nacionais com realidades sociais. Em A era dos extremos, Hobsbawm descreve a importância que o comunismo teve durante o século XX. Para o autor, "o comunismo soviético proclamou-se um sistema alternativo e superior ao capitalismo, e destinado pela história a triunfar sobre ele". De fato, durante o século XX muitos acreditavam nisso, mesmo nos países do Ocidente. (HOBSBAWM, 1995, p. 63).

Seria, então, a partir da tomada de consciência de classe $^{2}$, que o comunismo poderia substituir o capitalismo empoderando os trabalhadores e tornando-os proprietários dos meios de produção:

Pode-se sintetizar a fórmula sugerida pelo Manifesto [Comunista] para fazer avançar a revolução proletária em três consignas básicas: somente a negação da propriedade privada é capaz de aglutinar as forças sociais comprometidas com o fim da exploração capitalista; somente a teoria revolucionária é capaz de catalisar o descontentamento anticapitalista de modo a transformá-lo em prática revolucionária geradora de novos horizontes históricos; somente a perspectiva comunista - a utopia de inverter a relação de dominação da

\footnotetext{
1 Thompson (2004, p. 09-10), entende classe, como "um fenômeno histórico, que unifica uma série de acontecimentos díspares e aparentemente desconectados, tanto na matéria-prima da experiência como da consciência. Ressalto que é um fenômeno histórico. Não vejo a classe como uma 'estrutura', nem mesmo como uma 'categoria', mas como algo que ocorre efetivamente [...] nas relações humanas. Ademais, a noção de classe traz consigo a noção de relação histórica. [...] é algo fluido que escapa à análise ao tentarmos imobilizá-la num dado momento e dissecar sua estrutura. [...] A relação precisa sempre estar encarnada em pessoas e contextos reais. Além disso, não podemos ter duas classes distintas, cada qual com um ser independente, colocando-as a seguir em relação recíproca. Não podemos ter amor sem amantes, nem submissão sem senhores rurais e camponeses. A classe acontece quando alguns homens, como resultado de experiências comuns [...], sentem e articulam a identidade de seus interesses entre si, e contra outros homens cujos interesses diferem [...] dos seus. [...] A consciência de classe é a forma como essas experiências são tratadas em termos culturais: encarnadas em tradições, sistemas de valores, ideias e formas institucionais. Se a experiência aparece como determinada, o mesmo ocorre com a consciência de classe. [...] A consciência de classe surge da mesma forma em tempos e lugares diferentes, mas nunca exatamente da mesma forma".

2 Para Thompson (1978, p. 149), "muita atenção teórica (muito do que é claramente histórico) foi dada à "classe", e muito pouco à "luta de classes". Na verdade, a luta de classes é o conceito anterior, bem como o mais universal. Para dizer de forma sem rodeios: as classes não existem como entidades separadas, olham ao redor, encontram uma classe inimiga e então começam a lutar. Pelo contrário, as pessoas se encontram em uma sociedade estruturada de maneiras determinadas (crucial, mas não exclusivamente, por meio das relações produtivas), experimenta a exploração (ou a necessidade de manter o poder sobre aqueles que exploram), identificam pontos de interesse antagônico, começam a lutar por essas questões e, no processo de luta, descobrem-se enquanto classe, essa descoberta se conhece como consciência de classe [nossa tradução].
}

Revista Em Debate (UFSC), Florianópolis, volume 17, p. 15-35, 2017. ISSNe 1980-3532 
tecnologia sobre o Homem e do passado sobre o presente - é capaz de transformar a negação do capitalismo em um salto de qualidade no processo civilizatório (SAMPAIO Jr, 1998, p. 84).

O capitalismo, por sua vez, "representa o governo de classe pelo capital [...] limita o poder do povo. [...] Não há capitalismo em que a vontade do povo tenha precedência sobre os imperativos [...] da acumulação [em que os] lucros não definam as condições mais básicas de vida" (WOOD, 2002, p. 8) ${ }^{3}$. No entanto, como propõe Gorender (1998, p. 51), "Enquanto perdurar, o capitalismo suscitará tendências anticapitalistas".

No Brasil, os comunistas começaram a se organizar em 1906 por meio do movimento operário e do I Congresso Operário Brasileiro, realizado em abril daquele ano, na cidade do Rio de Janeiro com a participação de cerca de 50 delegados de 30 organizações diferentes. Nos anos seguintes, a influência da revolução chinesa de 1912, da mexicana (1910-1912) e, principalmente, da Revolução Russa, em 1917, abriu caminho para a criação, em 1922, do Partido Comunista do Brasil - PCB, em Niterói/ RJ.

Logo após o congresso de fundação, o governo de Epitácio Pessoa tornou o partido ilegal, condição em que passaria 61 dos seus quase 100 anos de existência.

De acordo com Rodrigues (2009, p. 11), no I Congresso “estavam presentes apenas nove delegados representando 73 membros de grupos comunistas. Entre os delegados, estavam dois intelectuais e sete trabalhadores [...]. Nenhum deles ocupava posição de destaque na vida política ou cultural do País”. Quase todos haviam iniciado sua militância política como anarquistas e só aderiram ao comunismo após a Revolução Russa. O PCB criara, então, uma cultura política capaz de aglutinar militantes entorno do partido:

\footnotetext{
Na cultura política do PCB (Partido Comunista Brasileiro) circulava dito interessante, expressão metafórica das motivações que levariam as pessoas a aderirem ao movimento comunista. Segundo essa formulação, haveria três fontes que sensibilizariam os indivíduos favoravelmente ao comunismo, correspondentes a órgãos do corpo humano: cérebro, estômago e coração. Alguns aderentes eram convencidos pelo cérebro, conquistados pela argumentação teórica e filosófica marxista; outros eram tangidos pelo estômago, ou seja, as necessidades materiais, a pobreza, e se identificavam com o comunismo na expectativa de verem sua situação social melhorar; já o terceiro grupo era tocado pelo coração, quer dizer, sua aproximação com a esquerda devia-se à força da sensibilidade (MOTTA, 2013, p.18).
}

\footnotetext{
${ }^{3}$ Afirmação corroborada por autores como Comparato (1998) e Quijano (1998).

Revista Em Debate (UFSC), Florianópolis, volume 17, p. 15-35, 2017. ISSNe 1980-3532
} 
É impossível pensar o século XX sem levar em consideração a Revolução Bolchevique de outubro de 1917 e como esta influenciou a militância comunista em todo o planeta. Os desdobramentos foram globais e duradouros. Para Hobsbawm (1995), a expansão alcançada pelo movimento dos sovietes só pode ser comparada às conquistas do Islã entre os séculos VII e VIII. Tal afirmação é corroborada por Gorender (1998, p. 52):

\begin{abstract}
Durante mais de um século, o processo histórico confirmou a previsão marxiana a respeito do potencial do proletariado. Este cresceu e incrementou sua capacidade de auto-organização à medida que crescia o capitalismo. A acumulação de capital também era uma acumulação de operários, o que produzia incoercível incremento da luta de classes anticapitalista.
\end{abstract}

Segundo Sampaio Jr. (1998), a teoria comunista foi formulada para atender às contingências da luta operária em países desenvolvidos da Europa Ocidental, o Manifesto Comunista trata de problemas de Estados nacionais consolidados. Porém, é no próprio Manifesto que está a metodologia capaz de solucionar esse problema, visto que "a categoria heurística de classe, na verdade não reivindica universalidade. A classe nesse sentido não passa de um caso especial das formações históricas que surgem da luta de classes" [nossa tradução] (THOMPSON, 1978, p. 150). Deve-se, portanto, compreender o processo histórico de cada formação social procurando encontrar as tendências concretas da luta de classes, definidas por Thompson (1979, p. 34) pela forma com que os homens vivem sua própria história. Para Sampaio Jr. (1998, p. 85):

\footnotetext{
Em economias capitalistas de origem colonial, como o Brasil, o sentido da formação social é dado pela longa transição da colônia de ontem para a nação de amanhã. O dínamo desta transição é o sentimento de profundo mal-estar da população com relação à situação de pobreza, irracionalidade, corrupção e instabilidade que caracteriza a vida nas economias periféricas. As esperanças e as aspirações destes povos polarizam-se, em consequência, em torno de um objetivo maior: controlar os fins e os meios do desenvolvimento.
}

Thompson articula a categoria experiência com cultura, constituindo uma junção entre as determinações objetivas do ser social e a ação humana, entre estrutura e processo. Entendendo cultura como componente imprescindível ao sujeito históricosocial, o autor compreende que a experiência vivida é sentida pelos indivíduos:

A experiência entra sem bater à porta e anuncia mortes, crises de subsistência, guerra de trincheira, desemprego, inflação, genocídio. Pessoas estão famintas: seus sobreviventes têm novos modos de pensar em relação ao mercado. Pessoas são presas: na prisão pensam de modo diverso sobre as leis. Frente a essas experiências, velhos sistemas conceituais podem desmoronar e novas problemáticas podem insistir em impor sua presença [...]. Pessoas que 
experimentam suas situações e relações produtivas determinadas como necessidades e interesses e como antagonismos, e em seguida 'tratam' essa experiência em sua consciência e sua cultura [...] e em seguida [...] agem, por sua vez, sobre sua situação determinada (THOMPSON, 1981, p. 181-182).

Quando o país foi sacudido pela Revolução de 1930, com Getúlio Vargas a frente, uma das primeiras medidas adotadas pelo novo governo foi a obrigatoriedade da sindicalização como forma de organizar os trabalhadores. Essa situação dificultava a atuação dos comunistas entre o proletariado, já que qualquer organização fora dos sindicatos era ilegal e as regras estabelecidas pelo governo impediam que a massa de profissionais que atuavam nas fábricas se filiassem:

\footnotetext{
A lei de sindicalização [...] estabelecia que cada sindicato devia ter pelo menos 30 pessoas de idade superior a 18 anos, dois terços dos seus membros, obrigatoriamente, oriundos do Brasil ou naturalizados. Para um estrangeiro se sindicalizar, deveria ter pelo menos 20 anos de residência ininterrupta no país (MARTINS, 1995, p 29).
}

Ainda em 1927, Luís Carlos Prestes, que viria a ser uma das principais lideranças do partido durante o século $\mathrm{XX}$, teve o primeiro contato com o partido que aceitou sua filiação em 1934. Mesmo ano em que o Integralismo despontava no Brasil, disseminando as ideias fascistas.

Em 1935, como resposta aos integralistas, foi criada a Aliança Nacional Libertadora (ANL), reunindo comunistas, liberais, tenentistas, e correntes operárias, para fazer oposição ao nazi-fascismo na política externa e interna (CARONE, 1982, p. 11). A ANL tinha como principais forças os tenentes dissidentes do movimento que levou Getúlio Vargas ao poder e o PCB com Prestes à frente.

Com cerca de 1500 núcleos pelo país em pouco mais de três meses, a ANL se expandiu chegado a quase todos os estados da federação em julho de 1935, quando Vargas a proibiu, utilizando a força policial para reprimir qualquer tipo de manifestação.

Para Thompson, o uso da força policial está longe de defender direitos e liberdades civis, contribuindo para uma sociedade mais livre. Eles manifestam, sim, "um interesse especial no status quo, [...] é próprio a essa profissão apoiar estatismos e ideologias autoritárias" (THOMPSON apud Müller, 2009, p. 8).

Em reação ao fechamento da ALN, Luís Carlos Prestes, apoiado pelos dirigentes do antigo grupo, pelo Partido Comunista e por setores das forças armadas, deu início, em novembro de 1935, ao Levante Comunista. Tal assertiva ocorreu, pois como afirma 
Wood (2013, p. 52), sobre os elementos que definem o Novo Socialismo Verdadeiro 4 , "é possível constituir e organizar uma força política no âmbito político e ideológico a partir de diversos elementos 'populares', unidos e motivados por razões puramente ideológicas e políticas, e independentes de conexões ou oposições de classes entre eles" [nossa tradução]. O primeiro ato do grupo foi deflagrado no dia 23 em Natal, Rio Grande do Norte, no dia seguinte teve continuidade em Recife, Pernambuco, e no dia 27, a revolta chegou ao Rio de Janeiro. Sem a adesão do operariado e restrita às três cidades, a rebelião foi violentamente esmagada pelas tropas do governo federal. Mais uma vez Wood (ibidem) completa: “a classe operária não produziu, apesar das expectativas de Marx, um movimento revolucionário; sua situação econômica não provocou o que se pensou que seria uma correspondente e apropriada força política" [nossa tradução].

Com o fracasso na tentativa de tomar o poder pelas armas, a militância comunista foi desmobilizada e a maioria dos dirigentes foram presos. Durante todo o ano de 1936, o país permaneceu sob estado de sítio e o governo intensificou a repressão até a instituição do Estado Novo, em 1937.

Somente em 1945, com o processo de redemocratização do país e com os militantes anistiados é que o PC tomou novo fôlego dentro da política brasileira. Nos dois anos seguintes, enquanto o partido esteve na legalidade, Prestes foi eleito Senador, os militantes assumiram dezesseis cadeiras na Câmara dos Deputados, com 109 suplentes, foram 46 deputados eleitos em 15 assembleias legislativas, a maior bancada no Distrito Federal, com 18 representantes. No estado de São Paulo, o partido elegeu 190 vereadores, alcançando as maiores bancadas em Sorocaba, Santos e na capital paulista, onde obteve 17 cadeiras, além da eleição do prefeito de Santo André.

Nesse período, o PC se aproximou dos partidos burgueses, criando alianças que a burguesia não cumpriu. Em 1947, um acordo entre o Partido Social Democrata - PSD, União Democrática Nacional - UDN e o Partido Liberal - PL, fez com que o governo de Eurico Gaspar Dutra cortasse relações com a União Soviética e colocasse, novamente, os comunistas na ilegalidade. Todos os militantes eleitos foram destituídos e

\footnotetext{
${ }^{4}$ Arcabouço teórico surgido durante a década de 1980 e criticado por Wood por, praticamente, rechaçar o projeto socialista da Luta de Classes. É definido pela autora por meio de sete pontos fundamentais. Ainda que Wood entenda que os teóricos pertencentes a esta corrente sejam, de certa forma, levianos, por reduzirem ou quase excluírem a importância do proletariado na revolução socialista, dois dos aspectos apontados pela autora (o de número 5 e o de número 1, respectivamente), se encaixam de forma a compreender o Levante Comunista de 1935.
}

Revista Em Debate (UFSC), Florianópolis, volume 17, p. 15-35, 2017. ISSNe 1980-3532 
a repressão se alastrou contra o $\mathrm{PC}$ e nos sindicatos.

Ilegal, o partido deu início a um processo autocrítico em relação as ilusões constitucionais por meio da Declaração de Janeiro de 1948, aprofundada com o Manifesto de Agosto de 1950, onde Prestes propunha uma Frente Ampla e criticava as organizações reformistas de esquerda:

\begin{abstract}
A formalização da hostilidade do partido para com partidos e organizações reformistas, porém, foi claramente realizada no manifesto de Prestes de agosto de 1950, conclamando à luta direta pelo poder através da criação de uma ampla organização popular conhecida como Frente Democrática de Libertação Nacional (FDLN). O programa de 9 pontos defendia um governo popular democrático, a "paz contra a guerra imperialista", a reforma agrária, o desenvolvimento da economia nacional, as liberdades democráticas para o povo, a melhoria das condições de vida, a educação obrigatória e gratuita e a formação de um exército popular de libertação nacional (CHILCOTE, 1982, p. 107-108).
\end{abstract}

Tal posição de Prestes aumentava alguns conflitos internos no PCB. Em 1952, por exemplo, José Maria Grispim, ex-deputado federal e membro do Comitê Central, foi afastado sob a acusação de direitismo por criticar as lideranças do partido, atacando a linha política do Manifesto de Agosto, a qual o dirigente considerava sectária (RODRIGUES, 2007, p. 497).

O partido permaneceu na ilegalidade até setembro de 1960, quando o V Congresso do PCB estabeleceu como prioridade a volta à legalidade. Para isso, os comunistas teriam de se adequar à legislação vigente e mudar o nome de Partido Comunista do Brasil para Partido Comunista Brasileiro. Essa mudança ocorreria de fato, em 1962, graças às reformas criadas sob o governo João Goulart.

\title{
Os militares chegam ao poder
}

As ditaduras latino-americanas da segunda metade do século XX estão ligadas aos efeitos da guerra fria ${ }^{5}$, (com o planeta dividido entre os signatários do Pacto de Varsóvia, entre os países socialistas encabeçados pela União Soviética, e os da Organização do Tratado do Atlântico Norte - OTAN, realizado entre os "Países do

\footnotetext{
5 Quando se trata da Guerra Fria, ortodoxias e ideologias se formaram desenvolvendo uma consciência que confirmava a polarização do planeta. Na União Soviética, por exemplo, a ideologia era a do antiimperialismo. Já no Ocidente, havia uma ortodoxia mais flexível, pragmática. A eficiência desta aparente flexibilidade sustentava-se na ilusão de que o sistema que prevalecia era a liberdade de expressão. Nesse nivelamento de conceitos, segundo Thompson, os autocratas de Washington se autorizavam a propagar o Ocidente como um "mundo livre". Ver mais em Müller (2009).
}

Revista Em Debate (UFSC), Florianópolis, volume 17, p. 15-35, 2017. ISSNe 1980-3532 
Norte", Europa Ocidental e Estados Unidos, principalmente), portanto não foram ações ocorridas localmente, mas que atingiram toda a América Latina:

Thompson demonstra como a Guerra Fria, independentemente de suas origens após a Segunda Guerra Mundial, operava com uma dinâmica própria, uma lógica interna e um conjunto específico de argumentos, o que ocultava o forte interesse dos estados envolvidos em sua continuidade. Ele percebe ainda que a reciprocidade das relações entre EUA e União Soviética era fundamental a essa lógica, um contexto em que uma forma de ação antagônica deveria ser sistematicamente igualada pelo antagonismo da resposta. Esse procedimento era determinante para a autorreprodução dos estabelecimentos militares e de segurança (MÜLLER, 2013, p. 11).

Thompson, porém, rejeita a aplicação dos conceitos de imperialismo ${ }^{6}$ e militarismo $^{7}$ para definir a guerra fria. Para ele, os sistemas desses blocos são complexos militares e industriais que a população civil é induzida a sustentar. Nesse sentido, o processo político serviria apenas para legitimar e justificar a própria reprodução. As elites governantes precisariam de uma permanente guerra para validar a dominação, os privilégios e prioridades, além de silenciar o dissenso, disciplinar a população socialmente e desviar a atenção da irracionalidade dessa operação (MÜLLER, 2009).

Para caracterizar o mundo a partir da Guerra Fria e da dinâmica do sistema de armamentos, Thompson cunhou o termo exterminismo:

\begin{abstract}
$\mathrm{O}$ exterminismo ${ }^{8}$ designa as características de uma sociedade - expressadas, em diferentes graus, em sua economia, política e ideologia - que a impelem em uma direção cujo resultado deve ser o extermínio de multidões. $\mathrm{O}$ resultado será o extermínio, mas isso não ocorrerá acidentalmente (mesmo que o disparo final seja "acidental"), mas como a consequência direta de atos anteriores da política, da acumulação e do aperfeiçoamento dos meios de extermínio, e da estruturação de sociedades inteiras, para estarem dirigidas para esse fim. [...] O exterminismo requer, para sua consumação, pelo menos dois agentes que entrem em colisão. Mas tal colisão não pode ser atribuída ao acaso, se ela foi há tanto tempo prevista, e se ambos os agentes, por uma política deliberada, se dirigiram a um rumo acelerado de colisão. [...] $\mathrm{O}$ exterminismo é uma configuração cuja base intelectual é o sistema de
\end{abstract}

\footnotetext{
${ }^{6}$ Lenin (2011), afirma que o imperialismo, como um estágio do modo de produção capitalista, resultou da exportação de capital e de mercadorias, da produção e distribuição centralizadas nos trustes e cartéis que começavam a surgir, da fusão entre os capitais bancário e industrial e da divisão do mundo em esferas de ingerência pelas potências capitalistas. Essa análise "se tornaria central no marxismo revolucionário dos movimentos comunistas após 1917 e dos movimentos revolucionários do Terceiro Mundo" (HOBSBAWM, 2203, p. 58).

${ }^{7}$ Para Harvey, o conceito misturaria as ações diplomáticas e militares de um Estado com o fluxo de poder econômico, seja ele por meio de capital, transferências monetárias ou tecnológicas, que percorrem espaços contínuos em direção contrária ou não a entidades territoriais. O que torna este tipo de imperialismo tão peculiar em relação a outras concepções de império é a "predominância da lógica capitalista, embora haja momentos em que a lógica territorial venha para o primeiro plano" (2005, p.36).

${ }^{8}$ Ver mais em Müller (2012).
}

Revista Em Debate (UFSC), Florianópolis, volume 17, p. 15-35, 2017. ISSNe 1980-3532 
armamento e todo o sistema de apoio econômico, cientifico, político e ideológico a esse sistema. [...] Daí o caráter do exterminismo nos anos [1980]. O exterminismo se confronta consigo mesmo. Ele não explora uma vítima, como o princípio do imperialismo: o exterminismo enfrenta um igual. A cada tentativa de dominar o outro, traz à existência uma contra força equivalente, e gera suas próprias contradições internas (THOMPSON apud MÜLLER, 2012, p. 311).

No cenário da guerra fria e na tentativa de manter o controle político sobre a América Latina, os Estado Unidos não podiam permitir que a vitória dos guerrilheiros cubanos servisse de exemplo, assim como deveriam barrar a organização popular nos países latino-americanos, abrindo espaço para as ditaduras impulsionadas pela criação de um inimigo em comum: o comunismo.

Segundo Müller (2009, p.16), “essa situação se estendia a tal ponto que, no interior dos países satélites [nesse caso as ditaduras latino-americanas], cada movimento político ou militar deveria ser aprovado pelo governo de Washington [...], reforçando os mecanismos de dominação" daquele país sobre o chamado Quintal da casa Branca.

Antes das ditaduras houve no continente formas de governo que tentaram resolver as demandas sociais. A Revolução Cubana, em 1959; o Chile de Allende; a Nicarágua com a Revolução Sandinista. No entanto, os experimentos socialistas foram, de acordo com Ianni (2012), desestabilizados, satanizados e destruídos por agências norte-americanas, em associação às elites, setores sociais e classes dominantes nativas:

\footnotetext{
A hegemonia ocidental construiu, em sua base ideológica, um forte determinismo moral, espelho do stalinismo soviético, espelhamento disfarçado de uma luta do bem contra o mal. No Ocidente, o sistema promoveu um estado de defesa contra o comunismo, criando-se no Ocidente a noção de um inimigo sempre presente. A ameaça era o comunismo revolucionário, que avançava - aparentemente triunfante - sobre Cuba, o Leste Europeu e os países em desenvolvimento (MÜLLER, 2009, p.10).
}

O sistema criado pela Guerra Fria era tão perverso que países aliados eram abandonados em detrimento de potências geopolíticas mais importantes. Thompson descreveu a natureza hipócrita desse sistema onde os países do Ocidente mantinham um relacionamento amigável com a ditadura argentina e lhe vendiam armas, sem nenhum constrangimento moral ou político. Para o autor a "guerra das Malvinas" seria uma das mais significativas consequências dessas vendas. Por outro lado, com a guerra em curso, os Estados Unidos abandonariam o aliado sul-americano, permitindo ao governo de Margaret Thatcher atacar os movimentos pacifistas, fazer os ingleses acreditarem que a bandeira do país fora provocada e encorajar o triunfalismo, aproveitando-se do conflito e orquestrando uma euforia popular em torno das mortes de soldados argentinos. O que Revista Em Debate (UFSC), Florianópolis, volume 17, p. 15-35, 2017. ISSNe 1980-3532 
garantiu, cerca de um ano após o termino dos combates, a reeleição da "Dama de ferro" e o fim o governo militar argentino.

Assim como em outros países da América Latina, o Brasil foi acometido pelo interesse na manutenção das oligarquias e a ditadura, iniciada em 1964, perdurou por 21 anos, até a primeira eleição, de forma indireta, de um civil para a presidência da República, em 1985. A população, porém, só teve o direito de votar para presidente em 1989.

Em princípios da década de 1960 as reformas sociais estabelecidas pelo presidente Goulart deram aos trabalhadores ganhos salariais condizentes com o aumento do custo de vida, enquanto no campo surgiram as ligas camponesas.

Em oposição às transformações sociais e estimulada pelos veículos de propaganda anticomunista do PSD, da UDN e da Igreja Católica, e financiados pelos Estados Unidos, a classe média engrossou o coro da elite e ajudou a preparar o terreno para o golpe militar (ARNS, 1985).

Para Souza (2008), "foi criado um inimigo". O comunismo. As elites do país espalharam o medo de que o Brasil seria tomado pelos comunistas e que, por isso, era preciso fazer algo antes que fosse tarde demais:

A ideia do comunismo foi um inimigo muito bem-criado, bem arquitetado em nível internacional, portanto as pessoas de fato acreditavam que havia esse perigo. Assim como parte dos revolucionários de esquerda acreditava que era possível, pelas reformas de base, uma reestruturação do país. A elite [...] acreditava que era preciso o poder militar para recolocar o país nos eixos (SOUZA, 2008, p 102).

Segundo Müller (2009), para explicar os perigos do processo político e ideológico da guerra fria, Thompson usou a metáfora da alteridade do Outro. Assim, essa unidade dentro dos blocos pode ser explicada, também, como preocupação e medo em relação aos "outros", à ameaça representada por eles, consolidando uma noção de "nós" em oposição a "eles". Ao perceber o "outro", "nós" podemos nos distinguir e, se o "outro" for criado enquanto uma ameaça, o vínculo entre "nós” é reforçado:

A guerra fria contribuiu, nesse sentido, para introjetar o "americanismo" na população norte-americana, reforçar o mito do sonho americano (American dream), tornando-o uma atração em oposição à tirania do "outro" mundo, tirânico e sem liberdade. Da mesma forma, a União Soviética representava-se a si mesma como a defensora do socialismo e o Partido como o titular da resistência ao imperialismo do Ocidente (MÜLLER, 2009, p.17).

Essa lógica de que o comunismo produziu um inimigo interno no Brasil 
permanece, ainda que em menor quantidade, no imaginário de parte da população brasileira e continua sendo propagada por setores civis e militares:

Um bando de mercenários a soldo da União Soviética [...], de [...] Cuba [...] e da China, tentam implantar o comunismo em nossa pátria. Atualmente, aqueles que restaram daquele grupo, mais uma quadrilha de aproveitadores, voltam a ameaçar a nossa liberdade, agora de maneira mais sutil beneficiados pela democracia da qual, hoje e sempre se aproveitam, para destruí-la e depois usá-la (FERREIRA, 2013, p. 4).

Mesmo as campanhas pacifistas da URSS eram usadas pela imprensa e pelos representantes do governo brasileiro para demonizar o PCB, afirmando que elas não passavam de "parte da propaganda comunista" e que eram meios sutis de mascarar os verdadeiros interesses dos militantes de estabelecer um novo conflito mundial e levar o caos aos "países livres e democráticos” (RIBEIRO, 2007, p. 66). "Thompson denuncia que, ao prover a informação para o consumo público, o sistema - governo, imprensa, etc. - acabava convencendo a opinião pública de que determinados temas eram de interesse nacional” (MÜLLER, 2016, p. 391). O controle dos meios de informação permite ao Estado a gerência dos questionamentos a ele dirigido:

Como consequência, são inimigos jurados da ordem, das instituições e da família brasileira. Por sua vez, o comunismo, um abismo de escravização, uma barbárie, é apresentado como crime, praga sinistra, atitude de permanente violência, processo violento e subversivo da ordem social, mas também como ditadura, ideologia totalitária, fantasia econômica delirante, materialismo histórico, nefasta doutrina (MARIANI, 1999, p. 144).

Não dá para pensar nesse processo de demonização do "mundo comunista" sem pensar no papel da imprensa:

[Para Tompson], a combinação de forças da mídia e do Estado [inglês] ${ }^{9}$ fez com que propostas alternativas ao status quo fossem, em grande medida, silenciadas. O controle do Estado sobre um ou mais meios de comunicação [...] legitimou uma política mais "responsável", em oposição aos pontos de vista não-ortodoxos e de dissenso. Até mesmo quando eventualmente alguma opinião antagônica era aceita e absorvida pelas agências de comunicação, essa absorção ocorria de forma deturpada. As ideias eram manipuladas e banalizadas de modo a adequar seu conteúdo aos valores propagados pela mídia. Afinal a indignação (da sociedade) - sempre apresentada como uma excentricidade - era um produto altamente vendável, um bom marketing. $\mathrm{Na}$ mídia, o dissenso não poderia aparecer como uma perspectiva coerente, competente, confiável ou legítima (MÜLLER, 2009, p.7).

\footnotetext{
9 Sem correr o risco de ser anacrônico ou fora de contexto, a análise feita por Tompson sobre a importância e influência da mídia na Inglaterra no período Thatcher pode ser aplicada ao Brasil do século XX. A relação intrínseca entre os meios de comunicação, o governo e a elite brasileira impedia qualquer tipo de dissenso, quando esse estava relacionado a oposição feita pelos comunistas.
}

Revista Em Debate (UFSC), Florianópolis, volume 17, p. 15-35, 2017. ISSNe 1980-3532 
Para Pinheiro (2013), logo nos primeiros momentos da ditadura brasileira, o aparato repressivo criado pelo novo governo partiu para cima dos comunistas. A primeira vítima de que se tem notícia foi o estivador e sindicalista Antogildo Pascoal Viana (AM), assassinado em abril de 1964. Seguiram-se a ele mais oito militantes. Para Carone (1982) e Napolitano (2013), o PCB sofreu de tal forma com o golpe militar que acabou sendo atropelado pelos acontecimentos e só conseguiu firmar uma posição sobre o que estava acontecendo cerca de um ano depois, com a Resolução de Maio, elaborada pelo Comitê Central do partido.

Mesmo com a repressão, no início do governo militar, ainda havia algum espaço e liberdade para a resistência através da arte e dos movimentos sociais. Nos primeiros anos da Ditadura, a luta se dava no âmbito da democratização do regime político e da sociedade existente. Até 1968, os estudantes, a classe operária e os artistas se encarregavam das lutas sociais:

O movimento social mais significativo pós-golpe militar de 1964 foi o de
resistência à ditadura e ao autoritarismo estatal, surgido a partir de várias
iniciativas, que congregavam em torno desse objetivo comum de resistência
segmentos das camadas populares e intelectuais e artistas. [...] o movimento
estudantil, [...] "movimento popular", com base em iniciativas da Igreja
Progressista e da Teologia da Libertação, das comunidades eclesiais de base
(CEBs) e das pastorais, dos centros de educação popular e de algumas
organizações civis comunitárias (SCHERER-WARREN, 1999, p.09).

Artistas protestavam com suas obras e as greves cresciam em Osasco, SP e Contagem, MG, retomando a luta sindical. Músicos levavam multidões aos Festivais da canção da TV Record e da Rede Globo com músicas que criticavam a ditadura. Disparada, de Geraldo Vandré, ou A Banda, de Chico Buarque podiam ser escutadas com certa liberdade, mas não sem incomodar o Governo. E, na política, o MDB assumia uma postura mais crítica com relação aos militares.

As manifestações estudantis eram cada vez mais frequentes em centros como Rio de Janeiro, Belo Horizonte, Brasília e São Paulo e vinham em um crescente, culminando em 1968 com a chamada "Passeata dos 100 mil", após a morte do estudante secundarista Edson Luiz:

Devagar a oposição ao regime vai adquirindo força no âmbito das ruas, das fábricas e das escolas, apesar de toda a repressão. Em março de 1968, no Rio, a polícia intervém contra uma manifestação de estudantes e mata o secundarista Edson Luís, de 18 anos. Como um rastilho de pólvora, espalham-se por todo o país manifestações públicas de protesto. Também as lutas operárias ressurgem com alguma vitalidade. Crescem o enfrentamento e as denúncias contra o Regime Militar, tendo as classes média urbanas

Revista Em Debate (UFSC), Florianópolis, volume 17, p. 15-35, 2017. ISSNe 1980-3532 
ocupado a frente das movimentações (ARNS, 1985 p.62).

Para Gaspari (2002), quando o ano de 1967 terminou, a esquerda e a direita estavam de acordo em um ponto: "a necessidade da criação de uma ruptura militarizada para o encaminhamento da divergência política". Os dois lados tinham a certeza de que, em pouco tempo, a guerra começaria e para a ditadura a eliminação do outro por meio da violência se apresentava como a melhor opção em relação ao dissenso:

\begin{abstract}
O esquema de raciocínio com que opera a reação é simples: o aparecimento de correntes de pensamento e de agrupamentos políticos que discrepam dos dominantes não resulta da realidade, da estrutura social, das condições econômicas, do próprio fenômeno político, em seu desenvolvimento; resulta da ação de "minorias solertes", que se "infiltram" aqui e ali no organismo social; identificadas, neutralizadas, reprimidas em suas ações, está tudo resolvido. [...] Isoladas as pessoas portadoras do vírus e submetidas ao tratamento adequado - tortura, prisão, demissão, exílio, banimento, etc. - a pátria estaria salva, a sociedade redimida (SODRÉ, 1986, p. 46-47).
\end{abstract}

Em outro artigo o autor continua: "para os que pretendiam acabar com a agitação, a solução parecia clara: amordaçar os agitadores. Essa foi a crença ingênua que, fundada no medo, moveu os atentados cometidos contra a cultura em nosso país, desde os idos de abril de 1964" (Idem, 2013, p.320).

Foi a gota d'água para que o governo baixasse o Ato Institucional $\mathrm{n}^{\mathrm{o}} 5$ (A-I5) onde definia o seu inimigo: “Atos nitidamente subversivos oriundos dos mais distintos setores políticos e culturais, comprovam que os instrumentos jurídicos estão servindo de meios para combatê-la e destruí-la [a 'revolução']". O isolamento dos militares foi responsável pelo fortalecimento da chamada "linha dura", que passou a agir de forma cada vez mais violenta na tentativa de forçar ainda mais o fechamento político do país.

Restabeleciam-se as demissões sumárias, as cassações de mandato, suspensões de direitos políticos [...]. Suspendiam-se as franquias constitucionais da liberdade de expressão e de reunião. Um artigo permitia que se proibisse ao cidadão o exercício de sua profissão. Outro patrocinava o confisco de bens (GASPARI, 2002, p. 340).

Dentre todos os 12 artigos existentes no ato, o de número 10 foi aquele que mais deu calafrios nos que lutavam contra a ditadura. Nele ficava suspensa a garantia de habeas corpus para crimes políticos, contra a segurança nacional ${ }^{10}$, a ordem econômica e social e a economia popular. Esse texto era a prerrogativa necessária para a

${ }^{10}$ Segurança Nacional, para Alves (1984), é um instrumento das classes dominantes, associadas ao capital estrangeiro, que o usam para legitimar e perpetuar, de forma não-democrática, um modelo baseado na exploração e no desenvolvimento dependente.

Revista Em Debate (UFSC), Florianópolis, volume 17, p. 15-35, 2017. ISSNe 1980-3532 
"epidemia" de prisões arbitrárias e tortura pelo país. Os militares passaram a ter o poder de prender quem quisessem por 60 dias, dos quais 10 poderiam ser de forma incomunicável $^{11}$.

Todas as emissoras de rádio e televisão, assim como as redações dos jornais escritos, passaram a contar com censores encarregados de filtrar textos, canções e programas que, de alguma forma, fossem encarados pelo governo como subversivos. Em 1974, com o AI5 em vigor, foram censuradas 452 peças de teatro pelo Brasil, número que não leva em conta a "censura de boca" e nem a autocensura que se instalou no país (PETRY, 2008). Essa administração e manipulação da mídia era o que Thompson definia como uma "crescente tendência na direção de um estado de segurança, em que as vozes de oposição são submetidas a dispositivos de constante vigilância, censura e repressão na mídia" (MÜLLER, 2016, 386).

Com o ato, o governo institucionalizou a repressão, a censura e a caça/cassa aos militantes antiditadura militar se intensificou com centenas de prisões e o exílio de muitos brasileiros, entre eles vários militantes do Partido Comunista:

O PCB foi massacrado de 1973 a 1976 por uma operação realizada pelo Exército, tratava-se da "Operação Radar", que tinha como objetivo liquidar o histórico operador político dos comunistas brasileiros. Essa era uma das medidas impostas pela geopolítica arquitetada por Golbery do Couto e Silva, para flexibilizar a ordem política brasileira (PINHEIRO, 2013).

Com o AI-5, as guerrilhas urbana e rural cresceram vertiginosamente, com o surgimento e a consolidação de líderes como Carlos Marighela, da Ação Libertadora Nacional - ALN, e Carlos Lamarca, ex-capitão do exército que passou a integrar os quadros da Vanguarda Popular Revolucionária - VPR. Naquele ano houve o surgimento de pelo menos 19 organizações armadas, como a VPR, a ALN, o Partido Comunista do Brasil - $\mathrm{PCdoB}^{12}$, e o Movimento Revolucionário 8 de Outubro - MR8. Praticamente todos estes grupos possuíam membros oriundos do PCB que "já carente de bases, desligadas do partido após a repressão policial de 1964, o PCB perderia até 1968 cerca de metade de seus integrantes remanescentes, adeptos das cisões que propunham a luta armada imediata" (RIDENTE, 2003, p. 208).

\footnotetext{
11 Antigos aliados do governo militar foram depostos de seus cargos e presos, como o governador do Rio de Janeiro, Carlos Lacerda, e Hugo Gouthier, ex-embaixador do Brasil em Roma. 66 professores universitários foram expulsos do país, entre eles, Fernando Henrique Cardoso, Caio Prado Junior e Florestan Fernandes. Artistas como Marília Pêra, Gilberto Gil e Caetano Veloso foram levados às carceragens militares.

${ }^{12}$ O PCdoB foi formado por dissidentes do PCB em 1962 e, em 1968, passou às ações armadas.

Revista Em Debate (UFSC), Florianópolis, volume 17, p. 15-35, 2017. ISSNe 1980-3532
} 
Durante a vigência do AI-5 o ataque aos comunistas se intensificou. Em Santa Catarina, por exemplo, a Operação Barriga Verde teve como clara intenção desarticular a militância comunista no estado. Nela, vários catarinenses considerados um sério perigo à estabilidade do governo (MARTINS, 2006), foram sequestrados, interrogados e torturados.

Posta em prática no final de 1975, a operação que durou até 1977 teve quarenta e dois presos. Os prisioneiros eram levados para Curitiba, PR, e depois trazidos de volta à Colônia Penal Urbano Salles, na cidade de Florianópolis. A maioria foi torturada, muitos deles nunca mais voltaram para casa e outros morreram na prisão.

As prisões iniciaram-se dia 4 de novembro pela manhã. Antes disso alguns estávamos sendo seguidos [...]. Falei prisões, mas [...] foram sequestros. Sem qualquer ordem de prisão ou aviso aos familiares. As nossas casas foram invadidas ilegalmente. Foram retirados sem ordem, livros, objetos de uso pessoal, não só dos que estavam nas mãos da repressão, mas também dos familiares. (FILHO, 1975 apud MARTINS, 2006, P. 19)

Com a Anistia em 1979, vários militantes que estavam fora do país retornam e passam a trabalhar na rearticulação do Partido Comunista que em 1985, com o fim da ditadura Militar, pôde voltar a funcionar como partido político legalizado.

\section{Algumas considerações}

Edward Palmer Thompson, um dos mais importantes historiadores do século $\mathrm{XX}$, além de estudar e levantar questionamentos e repostas acerca da formação da classe trabalhadora inglesa, do conceito de burguesia e da luta de classes, também foi capaz de cunhar categorias muito caras aos pesquisadores e historiadores de todo o mundo, uma destas categorias foi a de exterminismo que aplicamos para a compreensão da repressão do Estado brasileiro na tentativa de eliminar a força política dos comunistas. Da mesma forma, o autor explorou o conceito da alteridade do outro, presente na história do PCB no medo contra o partido propagado pela imprensa e pelas elites econômicas.

Portanto, a história do Partido Comunista, o mais antigo em atividade no Brasil, possui quase 100 anos de idas e vindas entre a legalidade e a ação política, e a ilegalidade e a marginalidade. Desde os primeiros momentos, após o congresso de fundação do partido, em março de 1922, Estado e elites econômicas se posicionaram de forma antagônica aos intentos dos militantes comunistas. Chama a atenção, então, a forma com que estes grupos trabalharam para demonizar a militância, construindo um Revista Em Debate (UFSC), Florianópolis, volume 17, p. 15-35, 2017. ISSNe 1980-3532 
inimigo perigoso à sociedade brasileira.

Com o golpe de 1964 a situação do partido piorou. O PCB que havia ganhado notoriedade na política nacional e estava próximo do governo do presidente João Goulart, foi empurrado uma vez mais para a ilegalidade, tendo de voltar a agir de forma clandestina na política e na tentativa de redemocratizar o país. Foram duas décadas de forte repressão, levando a sequestros, prisões, sessões de tortura e, em muitos casos, a morte. Foi, sem sombra de dúvidas, o período mais violento da história da militância comunista no país, no entanto, desde os primeiros momentos de existência do Partido Comunista do Brasil, no início do século XX, as elites se articularam para, juntamente com os veículos de imprensa e com o governo, impedirem os militantes de agirem, seja por meio dos sindicatos, seja pela via eleitoral: "a burguesia está sempre pronta a reconhecer as virtudes das classes servis quando as encontra: facilmente influenciada, leal, vivendo pacientemente no sótão, desempenhando de forma dedicada um serviço a 'toda a comunidade"' (THOMPSON, 2009, p. 13). Ser militante comunista no Brasil, portanto, sempre foi um risco e sempre veio acompanhado de medo e coragem. Medo da repressão e coragem para enfrentá-la. A luta encarnada pelos comunistas se ancorava numa vivência em comum pela possibilidade da conquista dos meios de produção:

Os valores não são pensados, nem chamados; são vividos, e surgem dentro do
mesmo vínculo com a vida material e as relações materiais em que surgem
nossas ideias. São as normas, regras, expectativas etc. necessárias e
aprendidas (e aprendidas no sentimento) no habitus de viver; e aprendidas,
em primeiro lugar, na família, no trabalho e na comunidade imediata. Sem
esse aprendizado a vida social não poderia ser mantida e toda produção
cessaria (THOMPSON, 1981, p. 194).

Na década de 1920 o Brasil viu nascer um partido de classe, surgido a partir dos fenômenos históricos, ocorridos no contexto dos primeiros anos do século $\mathrm{XX}$, das revoluções estrangeiras e da formação de um contingente operário brasileiro, efetivamente decorrente das relações humanas. Formado como resultado de experiências comuns entre os seus militantes, somando experiências sociais e teoria, articulando interesses entre si, e contra a burguesia brasileira presente, inclusive, no controle do Estado. Thompson compreendia a experiência humana como um processo histórico dialético entre o sujeito social e a consciência social. A consciência de classe, portanto, seria a maneira como essas experiências são culturalmente tratadas, são a experiência vivida e a experiência percebida. A luta de classe aqui, portanto, seria inevitável em uma sociedade estruturada de maneira a garantir a exploração de muitos 
por alguns em um antagonismo de forças políticas e sociais, evidentemente que a elite econômica do país reagiria a constituição de uma força que ameaçava o status quo de forma diametralmente desigual, utilizando todo o aparato jurídico e repressivo do Estado que lhe estivesse às mãos.

Essa situação ficou ainda mais evidente durante a guerra fria. A divisão do mundo em dois blocos antagônicos e recíprocos, como propôs Thompson, elevou a "guerra" aos comunistas a outro patamar. Eles eram os inimigos, não só do Brasil, mas de todo o Ocidente e, por isso, deveriam ser combatidos e exterminados. Eram o "outro" a ser rechaçado, a ameaça que reforçava o vínculo entre o "nós" ocidental.

O exterminismo, como o enfrentamento de um igual, de uma burguesia nacional e uma força política como os comunistas que, mesmo durante a ditadura e os períodos anteriores em que esteve na ilegalidade, se mostrava pronto para se colocar como uma oposição organizada e ampla, foi levado a cabo pelo Estado e pelo aparato repressivo deste para eliminar toda a dissidência de pensamento dos comunistas brasileiros. Ainda assim, a cada tentativa de dominar os militantes, estes continuaram a luta criando uma contra força pela legalidade do partido político e pelo fim das diferenças de classe da sociedade brasileira, deixando claro que a luta internacionalista só teria fim quando, como propôs Marx, o capitalismo der lugar a um modo de produção que priorize os trabalhadores em vez do capital.

Os militantes não se abstiveram da luta pela democratização do país e/ou da revolução proletária, não estiveram submetidos aos caprichos das elites que se utilizavam do processo político para legitimar e justificar a própria reprodução, a dominação, os privilégios e as prioridades, ainda que os esforços destas para silenciar o dissenso e disciplinar a população socialmente por meio do medo do comunismo tenha sido uma constante durante quase todo o século XX, numa mistura de exterminismo e alteridade do outro.

\section{Referências}

AGOST, Aldo. Balanço dos comunistas europeus. In: MAZZEO, Antônio Carlos; LAGOA, Maria Izabel (Orgs). Corações Vermelhos: Os comunistas brasileiros no século XX. São Paulo: Cortez, 2003, p. 11-23.

ALVES, Maria Helena Moreira. Estado e oposição no Brasil (1964-1984). $2^{a}$ ed. Petrópolis: Vozes, 1984. 
ARNS, D. Paulo Evaristo. Org. Um relato para história: Brasil nunca mais. $6^{\mathrm{a}}$ ed. Rio de Janeiro, Vozes, 1985.

CARONE, Edgard. A Terceira República (1937-1945). 2. ed. São Paulo: Difel, 1982.

CHILCOTE, Ronald H. Partido Comunista Brasileiro - conflito e integração 19221972. São Paulo: Biblioteca de Ciências Sociais, 1982.

COMPARATO, Fábio Konder. Previsões e ilusões. Estudos Avançados, São Paulo, n. 34, vol. 12, set./dez. 1998, p. 57-60.

FERREIRA, J. G. Ao cadete do meu exército. Disponível em: <http://pt.calameo.com/read/001819598fc06e2e092d7> acessado em: 10/12/2013.

GASPARI, Elio. A ditadura envergonhada. São Paulo, Companhia das Letras, 2002.

GORENDER, Jacob. O que está vivo e o que está morto no Manifesto Comunista? Estudos Avançados, São Paulo, n. 34, vol. 12, set./dez. 1998, p. 50-53.

HARVEY, David. O Novo Imperialismo. $2^{\mathrm{a}}$ ed. São Paulo: Loyola, 2005.

HOBSBAWM, Eric. Era dos extremos: O breve século XX - 1914-1991. $2^{\text {a }}$ edição, São Paulo: Companhia das Letras, 1995.

A Era dos Impérios (1875-1914). $8^{\circ}$ Ed. Paz e Terra: Rio de Janeiro, 2003.

IANNI, Octávio. Enigmas do pensamento latino-americano. Disponível em: $<$ http://www.iea.usp.br/publicacoes/textos/iannienigmas.pdf/view?searchterm=Enigmas +do+pensamento+Latino> acessado em: 25/07/2012.

LENIN, Vladimir. Imperialismo: fase superior do capitalismo. 1916. Disponível em: < http://www.dominiopublico.gov.br/pesquisa/PesquisaObraForm.jsp > acessado em: 10/11/2016.

MARIANI, Bethania. O PCB e a imprensa: os comunistas no imaginário dos jornais (1922-1989). Rio de Janeiro: Revan; Campinas, São Paulo. UNICAMP, 1998.

MARTINS, Celso. Os comunas: Alvaro Ventura e o PCB catarinense. Florianópolis, Ed. Paralelo 27 - Fundação Franklin Cascaes, 1995.

Os quatro cantos do sol: Operação barriga verde. Florianópolis, Ed. Da UFSC - Fundação Boiteux, 2006.

MARX, Kalr; ENGELS, Friedrich. Manifesto do Partido Comunista. Disponível em: < http://www.pcp.pt/publica/edicoes/25501144/manifpc.html> acessado em: 1\%/11/2013.

MOTTA, Rodrigo Patto Sá. A cultura política comunista. In: NAPOLITANO, Marcos, et. al. Comunistas brasileiros: cultura política e produção cultural. Humanitas; Editora Ufmg: Belo Horizonte, 2013, p. 15-39. 
MÜLLER, Ricardo G., "A ideia de exterminismo em E. P. Thompson: realismo e contradição". In: MISSE, Michel e WERNECK, Alexandre (orgs.). Conflitos de (grande) interesse: estudos sobre crimes, violências e outras disputas conflituosas. Rio de Janeiro: Garamond e FAPERJ, 2012, p. 305-336.

Exterminismo e luta de classe em E. P. Thompson: contradição e realismo. In Conferência Anual da International Association for Critical Realism - IACR, 12., 2009, Niterói/RJ, Anais... Tópicos Temáticos 2009 [s. n.].

Exterminismo e utopia: a estratégia pacifista de E. P. Thompson. In International Conference Strikes and Social Conflicts, 3., 2016, Barcelona, Anais... Combined historical approaches to conflict, 2016, pp. 384-402.

Exterminismo em E. P. Thompson: luta de classe e humanismo. Projeto História, São Paulo, n. 48, Dez. 2013, p. 01-36.

NAPOLITANO, Marcos. A estranha derrota. In: , et al. Comunistas brasileiros: Cultura política e produção cultural. Editora Ufmg: Belo Horizonte, 2013, p. 317-339.

PETRY, Cristóvão. Org. DERETI, Miraci. Os palhaços: texto teatral censurado em 1968. Florianópolis, Ed. Nauemblu \& Arte, 2008.

PINHEIRO, Milton. A ditadura militar no Brasil (1964-1985) e o massacre contra $P C B$. Disponível em: <http://resistir.info/brasil/massacre_pcb.html> acessado em: 10/03/2013.

QUIJANO, Aníbal. Un fantasma recorre el mundo. A atualidade do Manifesto na periferia do capitalismo. Estudos Avançados, São Paulo, n. 34, vol. 12, set./dez. 1998, p. 77-82.

RIBEIRO, Jayme Fernandes. Os "inimigos da paz": estado, imprensa e a repressão ao movimento dos "partidários da paz" no Brasil (1950-1956). SAELUM - Revista de história, João Pessoa, n.17, jul./dez. 2007.

RIDENTE, Marcelo. Nota sobre o PCB, suas dissidências armadas e Carlos Marighella. In: MAZZEO, Antônio Carlos; LAGOA, Maria Izabel (Orgs). Corações Vermelhos: Os comunistas brasileiros no século XX. São Paulo: Cortez, 2003, p. 207-217.

RODRIGUES, L.M. "O PCB: os Dirigentes e a Organização". In: FAUSTO, Boris (org.). História Geral da Civilização Brasileira. $9^{\text {a }}$ Ed. Rio de Janeiro: Bertrand Brasil, t. 3, v. 10, 2007.

Partidos e sindicatos: escritos de sociologia política. Rio de Janeiro: Centro Edelstein de Pesquisas Sociais, 2009.

SAMPAIO Jr., Plínio de Arruda. O que está vivo e o que está morto no manifesto comunista? A atualidade do Manifesto na periferia do capitalismo. Estudos Avançados, São Paulo, n. 34, vol. 12, set./dez. 1998, p. 83-86.

Revista Em Debate (UFSC), Florianópolis, volume 17, p. 15-35, 2017. ISSNe 1980-3532 
SCHERER-WARREN, Ilse. Movimentos sociais no Brasil contemporâneo. In: História, debates e tendências. Passo Fundo: Universidade de Passo Fundo, 1999, p. 09-21.

SODRÉ, Nelson Werneck. História da História Nova. Petrópolis: Vozes, 1986.

O terrorismo cultural. Revista Civilização Brasileira, Rio de Janeiro, n. 1, maio/1965, p. 239-297.

SOUZA, Sirlei. Resistência em tempos sombrios. In: THIAGO, Raquel S. (Org.). Tempos de Joinville. Joinville: Editora da Univille, 2008. p. 101-105.

THOMPSON, E. P.. A formação da classe operária inglesa. São Paulo: Paz e Terra, 2004.

Senhor, escrevendo a luz de Velas. TAVOLARO, Lília Gonçalves Magalhães; NEGRO, Antonio Luigi. [Tradução]. In ArtCultura, Uberlândia, v. 11, n. 19, jul.-dez. 2009, p. 7-14.

Eighteenth-century English society: class struggle without class? Social History - Taylor \& Francis, Cambridge, vol. 3, n. 2, May 1978, p. 133-165.

Tradición, revuelta y consciencia de classe: estudios sobre la crisis de la sociedad pré-industrial. Barcelona: Crítica, 1979.

A miséria da teoria ou um planetário de erros. Rio de Janeiro: Zahar, 1981.

WOOD, Ellen M. Democracia contra Capitalismo. São Paulo: Boitempo, 2002.

2013.

Uma política sin classes? El post-marxismo y su legado. Buenos Aires: RYR, 